\title{
UNIVERSUM
}

\section{EL IMAGINARIO DE LAS RUINAS DESDE UNA NOSTALGIA REFLEXIVA EN ADICIONES PALERMITANAS DE GERMÁN MARÍN}

The Imaginary of the Ruins from a Reflexive Nostalgia Adiciones palermitanas by Germán Marín

\section{Mariela Fuentes Leal ${ }^{1}$ iD}

'Universidad de Concepción, Facultad de Humanidades y Arte, Departamento de Español, Concepción, Chile. mariefue@udec.cl

\section{RESUMEN}

El siguiente artículo examina el imaginario de las ruinas en Adiciones palermitanas (2016) de Germán Marín, donde coexisten dos tiempos disímiles, pasado y presente, a cargo de la voz anacrónica de su narrador protagonista y el administrador del hotel Palermo, tipos de flâneur cuya nostalgia reflexiva, que reúne el deseo y el pensamiento crítico, funciona como medio de sobrevivencia en una ciudad en ruinas desde mediados del siglo XX hasta albores del siglo XXI.

PALABRAS CLAVE: ruinas; nostalgia reflexiva; ciudad de Santiago; flâneur; Germán Marín.

\section{ABSTRACT}

The following article examines the imaginary of the ruins in Adiciones palermitanas (20r6) by Germán Marín, where there two dissimilar times, past and present, coexist, in charge of the anachronistic voice of its protagonist narrator, and the manager of Palermo hotel, types of flâneur whose reflective nostalgia, which brings together desire and critical thinking, functions as a means of survival in a ruined city from the midtwentieth century to the dawn of the twenty-first century.

KEYWORDS: ruins; reflective nostalgia; city of Santiago; flâneur; Germán Marín. 


\section{INTRODUCCIÓN}

El extenso proyecto literario de Germán Marín representa una poética de las ruinas vinculada a sus preocupaciones literarias, culturales, políticas y personales en el Chile del siglo XX y albores del siglo XXI'. Su escritura, con una sintaxis enrevesada y digresiva, contiene vasos comunicantes entre un libro y otro mediante la aparición frecuente de acontecimientos, espacios y personajes vinculados a su propia historia y la de un Chile, rasgado por el golpe militar de 1973, y cuyas esquirlas a veces reflotan en los escenarios actuales. Marín aporta a la comprensión del pensamiento y el sentir de la cultura chilena, con "cierta clase de memoria íntima de nuestra identidad" (Bisama 86), empalmando el recuerdo colectivo con el individual, a partir de lo cual surge la nostalgia como "un término moderno para denotar el dolor de sentirse desplazado, fuera de lugar y el anhelo que se asocia a eso" (Sanfuentes 435).

En este sentido, algunas de las últimas novelas de Germán Marín apuntan a una estética afín a la melancolía y la ruinosidad, con sus longevos protagonistas, de lento caminar y con apremios económicos, quienes recorren la ciudad de Santiago, acompañados de una "libreta de notas" entre sus manos. Figuras anacrónicas y deterioradas que sobreviven con oficios menores, tales como: un ventrículo anónimo que espera su jubilación, un viejo vendedor de alimento para perros y un funcionario jubilado de la biblioteca nacional ${ }^{2}$. Todos ellos, alejados de las nuevas prácticas laborales y de entretención se desplazan por paisajes urbanos que muestran la absolecencia de objetos vinculados a hábitos y costumbres del pasado, los cuales muchas veces son empleados como materia prima en las notas manuscritas de los narradores protagonistas, cuyo ejercicio pendula entre la memoria y la reflexión. De esta manera, la escritura de Marín se empeña por unir el pasado y el presente en torno a una modernidad "contradictoria, crítica, ambivalente (que) reflexiona sobre la naturaleza del tiempo; en ella se combinan la fascinación por el presente con la añoranza de otra época" (Boym 49). En el caso de Notas de un ventrílocuo, la ventriloquía es un "disfraz de la escritura" (Bisama 2013), que consigna el habla pretérita de la figura del protagonista y sus muñecos a "un Chile perdido y de oficios perdidos" (Careaga 48), capaz de secuenciar "la cartografía de un país que sólo existe como ficción" (Bisama 2013). No obstante, en aquella novela el pasado y el presente convergen en forma paradójica alrededor de la precariedad citadina, "así, gran parte de su fuerza radica en cómo percibe a una ciudad y un país cambiados irremediablemente

\footnotetext{
${ }^{1}$ Desde su novela Fuegos artificiales (1973), pasando por la trilogía Historia de una absolución familiar (Círculo vicioso, 1994, Las cien águilas, 1997 y La ola muerta, 2005), Un animal muerto levanta la vista (El palacio de la risa, Idola y Cártago, 2003) y las novelas La Segunda mano (2009), El guarén (2012), Notas de un ventrílocuo (2013), Tierra amarilla (2014), Bolígrafo o Sueños Chinos (2016) hasta Adiciones palermitanas (2016).

${ }^{2}$ Nos referimos a las novelas Notas de un ventrílocuo, Bolígrafo o los sueños chinos y Adiciones palermitanas, respectivamente.
} 
pero que, milagro torcido, continúan siendo idénticos a sí mismos" (Bisama 2013). La misma lógica se repite en Bolígrafo o los sueños chinos (2016), donde el protagonista también tiene una visión desencantada de un mundo casi extinguido, el que ha sido remplazado por una sociedad que sigue los criterios de estandarización de la industria, exalta el auge de la tecnología y el consumo en desmedro del valor cultural de los espacios, los oficios y las tradiciones. Por ejemplo, el protagonista de esa novela se distancia de las nuevas estrategias de comercialización, como el marketing, porque:

No sé nada de este, quedado de mi parte en los rudimentos del comercio actual, como lo demuestra de paso, también en la informática, la ignorancia supina ante el uso del computador. Ayer alguien me dijo que los viejos carteros, antiguamente de azul, están desapareciendo, así como no hace mucho los buzones en las esquinas fueron eliminados. Cabe sospechar que a este paso, de pronto, los vendedores como uno saldrán de la palestra diaria, al igual como sucedió con los talabarteros, los fotógrafos ambulantes, los canillitas, los estiradores de somieres, los buhoneros, las gitanas de la suerte, los organilleros y gentes de otros oficios (62).

El descontento e incomodidad del protagonista por los avances del progreso en la ciudad se expresan cuando retrata la ciudad de Santiago en Bolígrafo o sueños chinos como una urbe en decadencia y fracturada, cuyas comunas disímiles manifestan la desigualdad entre quienes viven en forma acomodada en el sector oriente de la ciudad y los otros sectores, una diferencia relacionada directamente con términos económicos y manifestada en paisajes urbanos contrapuestos: espacios amplios/reducidos. En este sentido, el protagonista de esta novela reflexiona sobre el sueño utópico de Chile como un estado colectivo albergado en nuestra conducta y cuestiona la unidad constitucional de nuestro país, develando su heterogenidad; en palabras de su protagonista "Chile en su aparente unidad constitucional es un país disgregado, hecho de retazos, de poblaciones aisladas, de culturas disímiles" (I48)3.

Por su parte, Adiciones palermitanas retrata la ciudad de Santiago a través de un conjunto de fragmentos alternados por dos voces intercaladas de una historia dentro de otra, por un lado, un bibliotecario jubilado de la Biblioteca Nacional, vetusto y anacrónico, a modo de doppelgänger de Marín ${ }^{4}$, escribe una novela sobre el hotel Palermo para hacer frente al hastío que le provoca el exceso de tiempo libre. Para Ramiro Rivas, aquel "desdoblamiento escritural le permite a Marín objetivar los problemas del personaje, desnudando todas sus falencias físicas, la desolación de una existencia precaria y su propia incapacidad, producto de una edad avanzada" (2017). Y, por otro

\footnotetext{
${ }^{3}$ A lo anterior, el protagonista agrega una crítica directa a la corrupción solapada, extendida a otras regiones del país, que llega hasta a crímenes impunes, como el caso Jorge Matute el cual fue "barrido bajo la alfombra causa de intereses locales". (33).

${ }^{4}$ Hay varias coincidencias entre el narrador protagonista y el escritor Germán Marín, entre las que se destaca la autoría del escrito "La Perfumada", el uso de la escritura manuscrita, su condición de exiliado, enfermo de la pelvis, aficionado a la lectura y el cine, etc.-.
} 
lado, la novela narra la vida de los habitantes del hotel Palermo que "en alguna u otra medida [han sido] derrotados por la vida" (Vial 2016). El narrador protagonista escribe sobre ellos con objeto de sobrevivir al tedio del presente, un tiempo con el cual no se identifica, pero que observa desde la distancia. De hecho, el protagonista se define como una de "las últimas voces de una historia que se extingue y que, según parece, declina sin otro contenido como herencia que su riqueza cultural y el horror político de haber desatado dos guerras mundiales, junto, además, de unas abominables dictaduras en América Latina" (го). De esta manera, aquel es un sobreviviente en ruinas, fracturado y melancólico, de las catástrofes ocurridas en el siglo XX, que emplea la nostalgia como recurso de sobrevivencia frente a nuevas formas de experimentar el tiempo, la historia y el progreso.

Por lo anterior, examinamos la novela Adiciones palermitanas como una obra que constata un imaginario de las ruinas donde prima la nostalgia reflexiva y coexisten dos tiempos disímiles, el pasado y el presente, elaborando una temporalidad heterógenea, una línea lateral y discontinua de evolución bajo el alero de la tradición off moderna propuesta por Svletlana Boym En el futuro de la nostalgia (200I). Dicho concepto plantea una interpretación alternativa de la temporalidad causada por el proyecto inacabado de la modernidad que permite la coexistencia entre los bastidores de tiempos híbridos, donde la reflexión y el anhelo son elementos indisociables, porque son distensionados al reunir el tiempo histórico y el tiempo individual al punto que los recuerdos individuales se entrecruzan con los colectivos en la llamada nostagia reflexiva. Esta asume la naturaleza irreversible del pasado y la finitud humana, centrándose "en la añoranza y en la pérdida, en el proceso imperfecto del recuerdo" (Boym 73), con signos de la memoria que "aprecia los fragmentos destrozados de [ella] y temporaliza el espacio" (Boym 84). De esta manera, los nostálgicos reflexivos "son conscientes de que existe un vacío entre la identidad y la semejanza; el hogar se encuentra en las ruinas o, de lo contrario, está tan cambiado y aburguesado que es imposible reconocerlo" (Boym 84). Por esto, Boym hace hincapié en que la falta de familiaridad y sensación de distancia impulsan a este tipo de nostálgico "a contar su propia historia, a narrar la relación que existe entre el pasado, el presente y el futuro" (Boym 84), pero reconociendo la pérdida de marcos de memoria colectivos.

En este sentido, los dos planos narrativos intercalados en Adiciones palermitanas cristalizan temporalidades heterógeneas, pasado y presente, que constatan un mundo en ruinas a cargo del narrador protagonista y del administrador del hotel Palermo. Aquel se desplaza a zonas tradicionales y poco visitadas de la ciudad de Santiago en busca de un pasado que casi ha desaparecido, y, el cual se encarga de centralizar a través de la creación de la historia imaginaria del 
hotel Palermo y su entorno en los años setenta. Este lugar representa la añoranza de fragmentos de un mundo decaído que temporaliza la ciudad para el personaje, pues le recuerda "la opulencia del pasado, representada en esos despojos en ruinas, en esas construcciones que alguna vez reunieron a lo más granado de nuestra sociedad, se han ido borrando del casco histórico de Santiago" (Rivas 2017). De esta forma, el jubilado bibliotecario retrata el espacio que ha aguantado el paso del tiempo y ha resistido los avances del progreso, y del cual el mismo se siente partícipe, en tanto:

yo sentía por ese sector de Santiago, sin existir ningún vínculo mayor, una suerte de respeto debido a su antigüedad, en la que a pesar de los cambios, aún se mantenían en pie ciertos rasgos propios que delataban un pasado mejor, inmersos desde luego bajo un silencio que hoy ya no existía, crecida la extensión de la ciudad al igual que el cáncer en una piel enferma (Ioo).

Aquel pasado es rescatado por el protagonista a través de una nostalgia reflexiva que enlaza las ruinas de lo real con las ruinas dentro de la ficción, es decir, aquellas surgidas desde el proceso de escritura cuando el narrador protagonista crea la historia del hotel Palermo en su condición deteriorada desde la arquitectura hasta la presencia de personajes menores, habitantes de la marginalidad que reconocen su periferia y aceptan su derrota. En este sentido, Patricia Espinosa señala que "el escritor de la novela y el conserje del hotel Palermo, su álter ego, se ubican en una suerte de bisagra, entre el pasado y presente, desde donde constatan las ruinas de sí mismos y de todo lo que los rodea" (7o). Por ende, el espacio de la escritura manuscrita, a cargo de un anciano precario y nostálgico, con un bolígrafo y una libreta notas, es el lugar donde se cristaliza la convergencia temporal a través de la cual el protagonista evadirá los malestares de la cotidianidad y resistirá a los nuevos modos de existencia. De esta forma, Adiciones palermitanas:

es obra de un Marín confundido y por lo mismo lúcido. Ningún escritor puede pretender tener las cosas claras y él va más allá. Por eso no intenta concluir nada de manera satisfactoria. Ni siquiera se interesa por el final salvo por alivio que le ocasiona llegar a él. Lo más certero es este acierto, que así nomás es la vida para algunos, una forma de evadir ("Adiciones palermitanas, de Germán Marín: cómo evadir el dolor crónico, 2016).

En efecto, se trata de evadir una ciudad enferma en el presente actual del protagonista, porque aquella le provoca una constante incomodidad y una sensación de pérdida frente al avance del tiempo y la ambigüedad de la modernidad, esta última expresada en la cartografía discontinua y el ritmo altisonante de Santiago donde la estética urbana ha centralizado lugares de consumo y comercio de una sociedad de masas, sumergida en la pasividad del anonimato y cuyos sujetos en la novela desconocen los lazos de cohesión social y autenticidad, pues "si nada interrumpe la tranquilidad del centro, rota en algunas oportunidades por las manifestaciones estudiantes, suelo alcanzar a pie hasta allí hundiéndome en el anonimato del público que, apresurado, sin rostro, resulta de alguna manera el país que somos" ( 182 ). 
En otros términos, la ciudad de Santiago aparece como una sinécdoque del Chile de hoy, un país donde predomina una lógica uniformadora de consumo en detrimento de un enriquecimiento cultural y social que ha dejado el país en ruinas según el protagonista, quien mira desde una nostalgia que resulta "un nuevo entendimiento del tiempo y del espacio [...] sería una especie de rebelión frente a la idea moderna de tiempo, historia y progreso" (Sanfuentes 445). En este sentido, el protagonista resulta semejante a la figura del flâneur en una etapa crepuscular, pues observa la ciudad desde su vejez, pero manteniendo distancia de ese ritmo citadino.

\section{EL IMAGINARIO DE LAS RUINAS}

El crítico alemán Andreas Huyssen (20iI) valora la posibilidad de leer la historia a partir de la oscuridad de nuestro tiempo reconociendo las promesas incumplidas de la modernidad a partir de un imaginario de las ruinas, surgido desde la memoria y el trauma en el siglo XX. En las letras chilenas, Germán Marín habita la historia desde una poética de las ruinas que da cuenta, al igual que el ángel de la historia de Walter Benjamin, de la catástrofe de nuestro país "que acumula sin cesar ruina sobre ruina y se las arroja a sus pies" (Benjamin 64). El anciano protagonista de Adiciones palermitanas inclina su rostro hacia la ciudad de un Santiago, antiguo y olvidado, examinando las contradicciones de su cartografía arquitectónica y develando su fragmentación. Por un lado, la ciudad está compuesta por sectores tradicionales de mediados del siglo XX, construcciones ruinosas que revelan los entresijos de una época ida y sus hábitos, los cuales han sido desplazados hacia las orillas de la urbe. Por otro lado, Santiago está conformado por una serie de edificios colosales, nuevos y concurridos, en la centralidad de la urbe, hacia donde la masa anónima de la novela dirige sus pasos en forma apresurada, lugares ricos en el plano económico, pero ruinoso en su cultura.

En este sentido, destacamos el potencial semántico de las ruinas, inestable y sugerente, extendido en este artículo a las definiciones de "destrozo, perdición, decadencia y caimiento de una persona, familia, comunidad o Estado", "Restos de uno o más edificios arruinados" (RAE), las cuales permiten investirlas "con diferentes atributos: históricos, estéticos, políticos" (Hell y Schönle 5), todos ellos entrecruzados en Adiciones palermitanas al dar cuenta de un imaginario de las ruinas que pone en relieve el desajuste de la cartografía de la ciudad de Santiago y un traslapo de temporalidades en ella, lo que evidencia conflictos originados por el desarrollo moderno impuesto sin mediaciones sobre la historia y la memoria, anulando formas de vida de ritmo calmado y sereno que chocan con el alboroto de la velocidad urbana actual. En relación con esto, el protagonista señala "las nuevas edificaciones levantadas al oriente, varias a gran altura, como así también las 
avenidas aptas para la velocidad, Santiago distaba de ser más bella que antes, al revés diría, aparecía gris y tortuosa a semejanza de su gente, bajo cuyo espacio vital hallaba, sin embargo, mi identidad, adormecida por el retiro" (I6). El personaje cuestiona el progreso de la ciudad y rechaza su actual estética y corporización, en tanto aquel segrega los espacios tradicionales, vinculados a la figura lánguida del propio protagonista y el fantasmagórico hotel Palermo y sus habitantes, y expresa el tránsito de un tiempo colectivo y cultural a uno individual y de consumo en Santiago. De esta manera, la novela ofrece un contraste entre la imagen de una ciudad enferma del siglo XXI, con sus modos ruidosos e inquietos, frente a barrios ruinosos de la misma ciudad a mediados del siglo XX, con ritmos silenciosos y calmados. Leemos:

luego de cruzar el barrio, se desgaja en unas pequeñas calles, diseñadas casi todas sus casas por una sencilla arquitectura. Propia de los años cuarenta. Constituye, yo diría, el sector de cierta clase media de Providencia que, salvo aún de la hipertrofia citadina, sobrevive en su entorno el Santiago que fue alguna vez, de viviendas de uno o dos pisos, algunas realzadas por unos menudos jardines, donde se advierten las glicinas y cardenales[...]en esas pequeñas arterias todavía se esconde la antigua paz de la ciudad que, rota alguna veces, interrumpe, venida de décadas enterradas, el grito plañidero del afilador de cuchillos y tijeras, acompañado de su caballete de metal. Así también, si la tarde aún no ha muerto se oye la música cargada de nostalgias de tal vez el último organillero, escuchándose por ejemplo el vals Mantelito blanco, de Nicanor Morlinare (59-60).

Aquí, se temporaliza el espacio de la ciudad de Santiago a través de la combinación de fragmentos de la memoria y la reflexión crítica del personaje en torno aquel lugar, tareas disímiles en apariencia que se conjugan dentro del término nostalgia reflexiva donde "los recuerdos más queridos no le eximen a uno de la compasión, las opiniones y la reflexión crítica" (Boym 84) como la reflexión realizada por los personajes centrales de la novela, quienes se desplazan por el tiempo a través de los recuerdos cuando pasean por la ciudad de Santiago observándola con acuciosidad, pero en diferentes modos.

Por un lado, el administrador del hotel Palermo a mediados del siglo XX escapa del hastío paseando por la ciudad "me agrada salir a tomar aire, tras haber permanecido atado al Palermo durante tanto tiempo, luego de la monotonía que me aprisionaba, sin otro derrotero que la calle misma. Libre por unas horas, intimo con la ciudad como si fuera una vieja amante" (I8I-I82). En la época referida, la ciudad aún seduce y cautiva. En cambio, en los albores del siglo XXI, cuando el longevo protagonista camina por la ciudad para escapar del aburrimiento se distancia de los lugares más modernos y centralizados de aquella, aunque a la vez observa a sus habitantes desde un salón de café o una plaza, con cierta curiosidad por el patrón uniforme e impersonal de la masa. No obstante, los fragmentos de la ciudad que seducen la vida del protagonista son las edificaciones tradicionales, a las que el progreso ha dado la espalda y ha descuidado, a pesar de que algunas 
habiendo sido un barrio de bien, habitado por las llamadas mejores familias de apellido, hoy sus calles resultaban, enmohecidas por la pobreza y el desencanto, unas sombras de los edificios que se encumbran en el centro, formados éstos en su mayoría por instituciones bancarias y empresas comerciales (69).

Frente a este escenario, el nostálgico protagonista opta por caminar hacia lugares más arrinconados, anacrónicos y arruinados, los que han preservado un pasado ligado a su propio recuerdo e intereses. Por ejemplo, la visita al anticuario del señor Ulloa, donde:

Me interesaba volver a observar, si es que aún permanecía a la venta, cierto escapulario conservado en la vitrina, formado por un banda de seda que portaba, bordada en una cara, gracias al hilo blanco de la propia seda, una imagen de la Virgen María, mientras en su envés se destacaba la figura de la diosa Afrodita, estampada a color [...] deseaba en particular examinar de nuevo el telégrafo inalámbrico que tenía en funcionamiento a través del sistema Morse, mediante cuyo aparato él se comunicaba con ciertos poseedores de ese servicio, tanto dentro como fuera del país (63).

El protagonista, en el primer caso, se refiere a la paradoja del encuentro en el mismo objeto entre una figura religiosa y una mitológica, extensión que puede llevarse acabo para entender algunas tradiciones en Chile, y en el segundo objeto, este da cuenta del interés del protagonista por entender su funcionamiento en relación a una red de telegrafistas que mantenían contacto entre ellos, todo lo cual expresa la nostalgia de aquel por recuperar formas prétericas que manifiesten "las raíces de nuestra propia vida de hoy [porque] las ruinas son lo más viviente de la historia" (Zambrano 408-409), lo que no ha sido destruido y que aún se conserva. No obstante, también surge la paradoja del flâneur cuando el viejo protagonista observa las multitudes anónimas de la ciudad como un espectador en ruinas que repara en "la calle formado por quienes pasaban, entre otros, por estudiantes, señoras, empleados, ciclistas. Esa gente que circula me entretiene, como si fuera la secuencia de una película que no cesa" (47). Un film en que él no participa, sino más bien observa los comportamientos metropolitanos donde su escritura es el arte de señalar los fragmentos de aquella vida opuesta a su mundo, el que está en retirada como

películas antiguas en blanco y negro con la participación de unos actores ya muertos. Si bien están ellas periclitadas, aun hablan de un mundo que me pertenece, como resultan esas imágenes carcomidas, llenas de manchas y rayas, limpias muchas de éstas en la actualidad gracias al reciclaje (17).

Por tanto, el protagonista es un sobreviviente de los pocos que aún persisten y "todavía quedan del derrumbe" (Io) que ha suscitado el progreso y el modelo neoliberal instaurado por la dictadura militar de 1973 .

Recordemos que la novela Adiciones palermitanas está escrita en base a dos rutas narrativas; por un lado, relata la condición ruinosa de un protagonista melancólico y solitario, achacado por 
dolencias físicas, quien se dedica a relatar su existencia cotidiana y el proceso de escritura de su novelita sobre el decadente hotel Palermo, y, por otro lado, narra la historia contada de aquel hotel que cobra independencia junto al tráfago diario de sus solitarios residentes. La tarea de escribir en base a la nostalgia reflexiva del protagonista constata la funcionalidad de esta como recurso de sobrevivencia frente a las circunstancias de su presente. "Si no fuera por el libro que estoy escribiendo, la jornada sería más larga y tediosa, recluido como paso buena parte del día desde hace casi dos años" (9). Este recurso no es nuevo en la narrativa de Germán Marínº, sin embargo, lo novedoso es la ancianidad del protagonista, quien a pesar de los achaques de la edad y presentarse como un ser en ruinas corporalmente decide pasear solo por su ciudad o a veces pasear a su vecina Violeta en sillas de ruedas para conversar sobre la cotidianidad y una vez recluido en su casa sobrellevar su hastío a través de la creación.

En tal sentido, la escritura sobre la figura decadente del hotel Palermo da cuenta de los espacios desatendidos en la ciudad de Santiago, aquel que en otrora fue una construcción portentosa y expresión de la bonanza salitrera de principios del siglo XX, ubicado cerca de la plaza Brasil y graficado en la portada del libro en forma invertida en la fotografía de una casona del barrio Brasil -tomada por Álvaro Hoppe-donde el viejo hotel estilo neoclásico se encuentra en la parte superior y un cielo apacible, cruzado por algunas nubes en la parte inferior.

Aquella fotografía de la obra representa una realidad transitoria y sublime captada en el breve momento en que las nubes transitan por sobre/bajo la antigua construcción que ha llegado a su vejez. Es una imagen que apela a una intertextualidad con un fragmento del libro Dirección única de Benjamin donde este señala que

las construcciones cuyas ruinas se elevan hacia el cielo resultan a veces doblemente hermosas los días claros, cuando la mirada se cruza, a través de sus ventanas o en sus partes más altas, con nubes que pasan. La destrucción reafirma, gracias al efímero espectáculo que abre en el cielo, la eternidad de aquellas ruinas (Citado en Durán 6).

La eternidad referida podría estar representada en la novela a través de la figura del hotel Palermo, porque este lugar entrelaza el pretérito dejado y el presente sugestivo en una escritura zigzagueante y ambigua que juega con las temporalidades y apunta tanto a un progreso moderno como a un tiempo nostálgico. La novela tuerce la temporalidad narrativa cuando las ruinas del

\footnotetext{
5 Por ejemplo, la escritura salva al narrador protagonista de la realidad del exilio en el diario de vida de la Trilogía Historia de una absolución familiar, en el caso de Bolígrafo o sueños chinos y extrapolado a Notas de un ventrílocuo y Adiciones palermitanas, la tarea de escribir se convierte en "una lucha personal contra el aburrimiento. Si no ¿qué?" (Ramírez, 20r6), dice Marín; pero ya no desde su condición de exiliado, sino desde los márgenes del sistema, adonde son relegados las personas ancianas en nuestro país.
} 
hotel Palermo aparecen no sólo como fragmentos físicos, sino también como elementos alegóricos que representan el oxímoron de "lo eterno transitorio", propuesto por Walter Benjamin, quien

apunta hacia ese interludio en que la historia se suspende y es contemplada en la cristalización de sus ruinas como [...] emblema de la muerte y la decadencia, una manera de relatar una historia que ya no puede ser concebida como una totalidad positiva (Avelar 58 ).

En el caso de Adiciones palermitanas, la historia está constituida de fragmentos, llenos de ambigüedad temporal y multiplicidad de sentidos, cuya constitución ruinosa actúa como una alegoría, es decir, "una expresión estética misma de la desesperanza" (Avelar 58) de un mundo en extinción. En otras palabras, ruinas concebidas a modo de sinécdoque, a saber, fragmentos "que tenemos en la mano dominamos espiritualmente todo el período de tiempo que arranca de su origen; el pasado con todos sus destinos y mutaciones se concentra del presente susceptible de intuición estética" (Simmel 192).

Una expresión valiosa que concierne a la constitución propia del hotel Palermo como lugar creado desde la imaginación y a la vez parte de lo real, el que es extrapolado a la ciudad, en tanto encarna los cambios de una época desde su presencia como una magnifica mansión familiar que destacaba "entre las vecinas, bastantes alicaídas" (19), construida en 1927, pasando por su proceso de abandono y transformación del hotel de medio pelo en los años setenta, hasta su (seudo) desaparición como icono arquitectónico neoclásico en la novela. En este sentido, Simmel señala la arquitectura como

el único arte en el que se salda con una paz auténtica la gran contienda entre la voluntad del espíritu y la necesidad de la naturaleza, en el que se resuelve en un equilibrio exacto el ajuste de cuentas entre el alma, que atiende a lo alto, y la gravedad, que tira hacia abajo (I8I).

Un equilibrio que se quiebra cuando "el edificio se degrada y se desmorona" (Simmel I82), como el hotel Palermo y sus construcciones vecinas, hasta llegar a un estado ruinoso en su materialidad compuesta por "techos de zinc oxidado y, cada cierto trecho, acompañada por algunas propiedades ya en ruinas, ofrecidas en venta según letreros en rojo, a punto de caerse ciertas murallas de adobe derruidas por la humedad, salvadas de los últimos terremotos" (24). Ruinas físicas que arrastran consigo también el ritmo más pausado de una época de tradiciones, cohesión social y ritos colectivos, tales como las sesiones de baile a las que acudía el administrador del hotel Palermo cada primer sábado del mes en el salón Monterrey. Reuniones arraigadas a sus vidas que apelan a "ágapes sociales, típicos del pasado, cuyo ambiente discreto y familiar ayudaba a moderar la convivencia juvenil, como también secundaba el trato de hermanos que nos dábamos" (66). Se trata de encuentros que aún conservan el afán gregario de sus individuos, antiguos modos de 
convivencias sociales cuyas interacciones físicas, cercanas y directas, giran sobre los pormenores de sus propias vidas y sus singularidades. Una añoranza que fue el precio pagado por el progreso según Andreas Huyssen, en tanto se da "la destrucción de las pasadas formas de vivir y estar en el mundo. No existía la liberación sin una destrucción activa" (I4). En la novela, la destrucción de esas formas de existencia aparece afín a la tecnología móvil, considerada una rareza por los personajes del hotel, la que surgió con el avance del progreso, lo cual es constatado en las palabras del administrador del hotel:

desde entonces hasta unos años después, en medio de diversos sucesos nacionales, todo prosiguió para él de manera más o menos semejante, si bien empezaron operar importantes cambios en el progreso, al grado de que sorpresivamente pudo darse cuenta, sobre todo de una temporada a otra durante las vacaciones, que empezaba a ser común, cualquier fuese la condición social, el uso de celulares, cuya modernidad permitiría, tiempo después, servir como cámaras, vaya el milagro del nuevo siglo (49).

La extrañeza referida es compartida por el protagonista en su escritura sobre la vida del hotel Palermo, basada en el uso de la memoria y el deseo, que "termina de pronto haciendo un puzzle, como sucede con el desorden cronológico y a veces sentimental, que casi siempre guarda la memoria" (72). En este sentido, el protagonista es un nostálgico que emplea la escritura como un modo de enfrentar la incomodidad en el presente y arrastra los recuerdos de una época pasada para sobrevivir al hastío del hoy. Sin embargo, él acepta el desvanecimiento de una promesa incumplida de regresar a un pasado ideal y acentúa más bien el espacio literario como un arma de creación y crítica basada en un imaginario de las ruinas que asocia a la nostalgia reflexiva y a la originalidad, en tanto ambos conceptos apelan a un pensar atento, reflexivo y crítico que permita construir alternativas futuras a un progreso lineal y homógeneo. En Adiciones palermitanas, este planteamiento proporciona un nexo entre la memoria personal y la colectiva del narrador protagonista, quien busca lugares vinculados a fragmentos de su recuerdo en que la "escena de las ruinas es una plataforma que incita las articulaciones de la memoria misma" (Masiello Ioo). Una estrategia de sobrevivencia que le da sentido a su presente desde las ruinas del deseo que repite y revive hasta el punto de crear un lugar fantasmagórico y familiar a su época de adultez plena para preservar un pasado y evidenciar una concepción heteróclita del tiempo que tiene su correlato en la incisión del yo. Respecto a esto, Francine Masiello señala "puede ser que las ruinas como tropo decimonónico por excelencia respondan a un nuevo concepto de tiempo interior dividido" (Io6). Un tiempo coincidente con una nostalgia reflexiva de Svetlana Boym que funciona como "rebelión contra la idea moderna de tiempo, el tiempo de la historia y del progreso" (Boym i6), el que se ha encargado de disociar la reflexión y el anhelo, es decir, el pensar y el deseo. Aquí, la novela añora un tiempo pretérito y a la vez encauza una constante reflexión tanto del narrador protagonista como del 
administrador del hotel Palermo, lo que revela que es en realidad un mismo sujeto, pero desdoblado. Además, la suma de los habitantes variopintos del hotel Palermo ejercen visiones de la vida y oficios de una época ida, reflejo de la caducidad de una época. No obstante, ese pasado aún respira en el presente crispado del protagonista, quien recuerda y se aferra a ciertos espacios desatendidos de la ciudad donde el tiempo parece haberse detenido. Por eso, a través de la nostalgia, el personaje

traza el espacio en el tiempo y el tiempo en el espacio, e impide establecer una distinción entre sujeto y objeto; tiene dos cabezas [...] una arqueología dual de la memoria y del espacio, y una historia dual de las ilusiones y las prácticas reales (Boym I9).

Una iconografía inventada/explorada de una temporalidad heterógenea utilizada como recurso de sobrevivencia por el personaje para enfrentarse a la ruina de su propia vida y su cultura, las cuales han sido destruidas tanto por la transitoriedad del tiempo y como por el progreso que arrasó con modos de vida más íntimos y originales. De tal forma, el narrador protagonista señala que "era la realidad que, estacionada en el pasado, me permitía entrar al espejo del tiempo y sobrellevar, sin salirme de la rutina diaria, la vida que practicaba, tal como acaso indican estos esquicios que he venido desarrollando" (64).

Una realidad captada a través de una escritura cercana al derrumbamiento cuyo escenario es "semejante a la vida, abierto y expectante, aunque pronto se ignorará qué viene después, la incógnita que representa el futuro dentro del escrito" (Marín iz). De esta manera, la estructura dicotómica entre lo factual y lo imaginario en la realidad del protagonista termina fusionándose en juegos de ficción. Como señala el epígrafe de Alberto Girri en la obra "parte de que todo es uno". Una sinécdoque que propone un tiempo y un espacio desequilibrados cuya borradura de fronteras entre imaginación/realidad y pasado/presente configura un imaginario de las ruinas frente al cual con estupor el narrador de la novela pregunta “QQué era ésta como verdad, sólo una fantasía?” (20I). Con la combinación de aquellos planos, se suscita un rechazo a la noción de tiempo "vacío" y "homogéneo" y, en cambio, se promueve un tiempo que acepta la coexistencia de temporalidades heterogéneas a partir de la memoria en que la experiencia singularizada profesa una ruina creativa de la voz sobreviviente de un mundo que se extingue: un mundo en ruinas. De esta manera, la novela presenta una catástrofe a doble compás tanto desde el presente de la ciudad de Santiago como desde el pasado representado por el hotel Palermo. En ambas el deseo que acompaña a la nostalgia se revela "como las más poderosas barreras contra la ruina" (Espinosa 20I7), pues permite superar el tedio cotidiano de la vejez e invita a permanecer en un continuo acecho o revisión del pasado. De este modo, la obra rescata historias menores a través de personajes del hotel que aluden 
a la dictadura de Pinochet, tales como: la señora Trinidad, un personaje altanero, quien toca piano y tenía un hijo fallecido "Miguelito [...] el muchacho, estudiante de arquitectura, pertenecía a Patria y Libertad, un organización de extrema derecha ligada a los uniformados" (IIO); la joven pareja de estudiantes universitarios inmolada en la habitación número 337 del hotel Palermo ante el inminente arresto de la fuerza policial, una pieza que nadie después se atreve a ocupar, lo que es una clara referencia a las presencias espectrales vinculada a las ruinas según María Zambrano; y por último, el viejo Cárcamo, habitante del hotel, un antiguo boxeador que trabajó para los servicios de inteligencia en el centro de tortura Villa Grimaldi.

Además, el protagonista acecha a la figura femenina para combatir su dolor físico, con su inquieta mirada voyerista y la "visión hambrienta de sus ojos" (II); y usa el fisgoneo para hacer frente a su "sequedad creativa" (25), porque le otorga la fuerza y la energía para seguir avanzando en su novela, "es algo que me secunda cuando quedo a solas, lejos de cualquier recurso" (26). En otras palabras, el deseo activa su imaginación y penetra en los resquicios de lo factual con la figura de Mónica, quien unifica ambos planos cuando dirige al protagonista al ya destruido hotel Palermo en la historia escrita por el protagonista. En ese momento, ambas historias toman una ruta común cuyo marco central será aquel hotel, confundiéndose las dos lecturas, a modo de juego de espejo en una ambivalencia del tiempo ligada a la nostalgia reflexiva, la que a su vez está vinculada a las ruinas que posibilitan la tarea de revelar "la conciencia de una ruptura insuperable del pasado que constituye la era moderna y a la vez el sentido de que un rastro valioso ha perdurado y necesita ser apreciado" (Hell y Schönle 5). En este sentido, el hotel Palermo devela los márgenes borrosos del tiempo cuya figura revela la supresión de fronteras, tal como se presenta el espejo a la entrada del hotel Palermo donde cada persona se refleja en ellos doblemente real. "Un detalle tal vez a tomar en cuenta", desliza el narrador de la novela y como señala el propio Marín "Todo es uno. Imaginación y realidad a la vez. Yo creo que muchas veces conforman un solo cuerpo" (Guerrero 20r6).

Una confusión en la obra que deja atónito hasta al propio protagonista cuando ve intacto el hotel Palermo en su propia realidad, creado y luegomdestruido en su propia escritura de ficción, descubriendo

enseguida para mi perplejidad que el Palermo, reluciente al costado la plancha de bronce con su nombre. Proseguía allí mismo en esa esquina, al lado de las casas vecinas, todas a maltraer, alicaído también el sector [...] intacto el conjunto de la pretérita casona bajo un color todavía amarillento, desvaído por el tiempo (20I).

Frente a este escenario revivido el protagonista asume la derrota de la ficción frente a la realidad y reflexiona sobre el tiempo de las ruinas en el hotel Palermo, el que resiste su borradura a 
pesar de su condición ruinosa, en tanto "nada es inocente: en presencia de las ruinas [...] entonces todo encuentro con las ruinas se vuelve dialógico. Es una manera de percibir pasado y futuro juntos" (Masiello roo). La nueva percepción temporal propuesta en Adiciones palermitanas cristaliza la búsqueda de una autenticidad de las ruinas de la historia a partir de un axioma sobre sí misma de "constelación significativa, tanto conceptual como arquitéctonica, que designa momentos de decadencia y digresión" (Huyssen 50). De tal modo, el hotel Palermo se mantiene en pie sin negar su estado decaído y ruinoso, aquel expresa el lado oscuro de la modernidad y su figura exhibe los embates del tiempo y las potencialidades del futuro de un imaginario de las ruinas que reconoce las derrotas y supera el triunfalismo del progreso y propone un imaginario de las ruinas que puede leerse como un "palimpsesto de mútiples representaciones y acontecimientos históricos [...] que privilegia la memoria y el trauma" (Huyssen 49). Por ende, la figura del hotel Palermo aparece como un espacio donde habita el secreto de las ruinas en base a un tiempo escurridizo y una dislocación de lo real, que "a pesar de los cambios que sufriera el inmueble en su puesta al día, conservaba aún, al mirar con atención los detalles del pasado, perdidos ahora en la vulgar existencia del Palermo que, por encima de la labor cotidiana, trataba de salvarlos de su progresiva decadencia" (39). En definitiva, se trata de entender cómo las ruinas son necesarias para generar un diálogo cuya heterogenidad temporal puede ser provista a partir de un imaginario de aquellas en base a una nostalgia reflexiva.

\section{CONCLUSIONES}

El imaginario de las ruinas en Adiciones palermitanas de Germán Marín establece la ciudad de Santiago como un espacio fragmentario que empalma la añoranza de un pasado y la reflexión de un presente a partir de una nostalgia reflexiva. Se trata de reconstruir un fragmento de lo pretérito, acompañado de la conciencia histórica del narrador-protagonista en el presente, quien valoriza la temporalización de los espacios y la convivencia entre el deseo y el pensamiento crítico. Desde esta tensión temporal, la novela resignifica el pasado a través de un imaginario de las ruinas que considera la transitoriedad del tiempo y el progreso en la ciudad de Santiago como elementos constitutivos de la configuración de espacios urbanos con un montón de residuos y ruinas, esto sin dejar de aludir en fragmentos que estas también están cruzadas por el golpe militar de i973.

En este sentido, el hotel Palermo funciona como un espacio de la memoria que genera una imagen alegórica de un mundo perdido que termina (seudo) demolido. Con esto, Marín examina la precariedad de la ciudad de Santiago que evidencia la caducidad de las construcciones y el fracaso 
de un proyecto de progreso, vinculado a la fractura sociocultural del golpe militar de 1973, a través de la deteriorada figura del hotel Palermo, la que al igual que el Palacio de la risa presentan un "significado a su identidad nacional: una casa en ruinas" (Rojo 302). Un lugar del fracaso y la derrota de personajes menores y simples del hotel Palermo que son deshabitados de la urbe alrededor de los años sesenta y luego sustituidos por una masa anónima en el ambiente alienante en la ciudad del siglo XXI.

En este escenario, la presencia del narrador protagonista por visibilizar ese imaginario de las ruinas es la de un cierto viejo flâneur, cuya nostalgia reflexiva no solo le permite sobrevivir en el presente recordando un pasado ido, sino también observar la ciudad de Santiago desde "una existencia gris cuya única ventaja es tener conciencia del minuto que respiro" (Marín 48). Una existencia pusilánime y distante que ve cómo el ajetreo diario metropolitano en las postrimerías de su vida choca con los sectores periféricos y abandonados de la modernidad, y manifiestan la fragmentación ruinosa de una época pretérita donde "rescatar de lo histórico, no es el hecho, sino lo que ha quedado de él; las ruinas" (Zambrano 409) para hacerlas dialogar y entender nuestro presente. En definitiva, se trata de sobrevivir al amparo de la escritura con un tono nostálgico reflexivo que permita enfrentar la derrota y el duelo incompleto en torno a un imaginario de las ruinas.

\section{RECONOCIMIENTOS}

El presente artículo se enmarca en el proyecto del Fondo Nacional de Desarrollo Científico y Tecnológico (FONDECYT) de Iniciación a la Investigación №III70585, del cual la autora es investigadora responsable.

\section{REFERENCIAS}

Avelar, Idelber. Alegorías de la derrota: la ficción postdictatorial y el trabajo del duelo. Editorial Cuarto Propio, 2000.

Benjamin, Walter. Ensayos escogidos. Ed. H.A. Murena. Buenos aires: Editorial el cuenco de plata, 2010.

Benjamin, Walter. Origen del Trauerspiel alemán. Buenos Aires: Gorla, 2012.

Bisama, Alvaro. "El último chileno". Revista Qué pasa. 28 de agosto 20I3: s.p. Disponible en https://cutt.ly/wmSoE22 
Bisama, Alvaro. Deslizamientos. Santiago: Ediciones Universidad Diego Portales, 2016.

Boym, Svetlana. El futuro de la nostalgia. Madrid:Antonio Machado, 2015.

Careaga, Roberto. "Soy un outsider a la maraña literaria". La Tercera [Santiago, Chile]. 16 de agosto 20I3. 48 .

Durán, Pablo Andrés. Paseando en las ruinas. Colombia: Editorial Kimpres Ltda., 2012.

Espinosa, Patricia. "El macho anciano". Las últimas noticias. [Santiago, Chile]. 6 de enero 2017. 7 o.

Frisby, David. Fragmentos de la modernidad. Madrid: Visor, 1992.

Guerrero, Pedro Pablo. "Germán Marín: Recuerdos de un sobreviviente". El Mercurio. [Santiago, Chile]. 6 de noviembre de 2or6: s.p. Disponible en https://cutt.ly/FmSoDoj

Hell y Schönle, (eds). Ruins of Modernity. Estados Unidos: Ducke University Press, 20 oro.

Huyssen, Andreas. Modernismo después del modernismo. Barcelona: Editorial Gedisa 201 .

Lazzara, Michael, Unruh, Vicky. Telling ruins in Latin America.New York, 2009.

"Adiciones palermitanas, de Germán Marín: cómo evadir el dolor crónico". El Líbero.rs de diciembre 2016: s.p. Disponible en https://cutt.ly/vmSoZUS

Marín, Germán. Bolígrafo o sueños chinos. Santiago, Chile: Ediciones Universidad Diego Portales, 2016.

Marín, Germán. Adiciones palermitanas. Santiago: Alfaguara, 2016.

Massiello, Francine: "Los sentidos y las ruinas". Revista Iberoamericana, año VII, nº 30, (2008)IO3-II2.

Matus, Álvaro. "Soy reaccionario de alma y progresista de vocación", en Revista de Libros de El Mercurio, 05 de agosto 2017. Ei6-Ei7.

Rivas, Ramiro. (2017). "Germán Marín, un escritor incómodo". Punto Final. 9 de junio 20I7: s.p. Disponible en https://cutt.ly/xmSo45B

Rojo, Grínor. "Germán Marín está de visita en El palacio de la risa". A contra corriente. Vol. II, No. 3, (2014) 297-304.

Sanfuentes, Olaya. "Nostalgias de un Santiago que se fue. Sentimientos de pérdida de "un mundo mejor" y criollismo literario a mediados del siglo XX". En Homo Dolens. Cartografías del dolor: sentidos, experiencias, registros. Santiago: Fondo de cultura económica, 2018. 435-45I.

Simmel, Georg. "Las ruinas". Sobre la aventura. Barcelona: Ediciones 62, 2002. I8I-I95.

Vial, Juan Manuel. "Al interior del hotel fantasma". i7 de diciembre 20r6: s.p. Disponible en https://cutt.ly/umS2rEo

Zambrano, María. "Las ruinas". La razón en la sombra. Ed. Jesús moreno Sanz. Madrid: Siruela, 2004. $408-410$. 